\title{
Music, maestro, please!
}

Neuroscientists are starting to discover how our brains process music. This involves distinct neural circuits, but a mystery remains. Why are melody, harmony and rhythm so important to us? Alison Abbott tunes in.

$\mathrm{M}$ usic stirs the soul. Mozart's Requiem has moved listeners for centuries. And today's masters of popular culture have made a fine art of using music to manipulate our moods: when Oliver Stone picked Samuel Barber's Adagio for Strings as the theme for his Vietnam epic Platoon, he knew that its plaintive tones would induce a surge of emotion among movie-goers.

Now, research is revealing the neural interactions that provoke these reactions, showing that our brains have distinct circuits for perceiving, processing and playing music. The neuroscientists behind these studies say that music provides an ideal model for studying how the brain integrates complex perceptual and behavioural tasks. But these researchers are also interested in answering a more fundamental question: what is music for?

After all, an appreciation of music confers no glaringly obvious advantage in the darwinian struggle for survival. Various theories have been put forward - that music promotes social cohesion, for example - but so far, none represents more than a plausible 'just so' story. Our love of music might merely be a pleasurable side-effect of the evolution of other perceptual abilities - representing, as cognitive neuroscientist Steven Pinker of the Massachusetts Institute of Technology has put it, "auditory cheesecake"1.

Each of our sensory organs delivers its information directly to its own specialized area within the temporal lobes of the cerebral cortex. These areas are divided into three hierarchical levels - primary, secondary and tertiary - according to the complexity of the data-processing task. Together, they build up our mental representations of the world.

But responding to a piece of music requires far more than the perceptual skills of the auditory cortex, a structure sitting in each of the brain's temporal lobes within a through the brain.

\section{Melody makers}
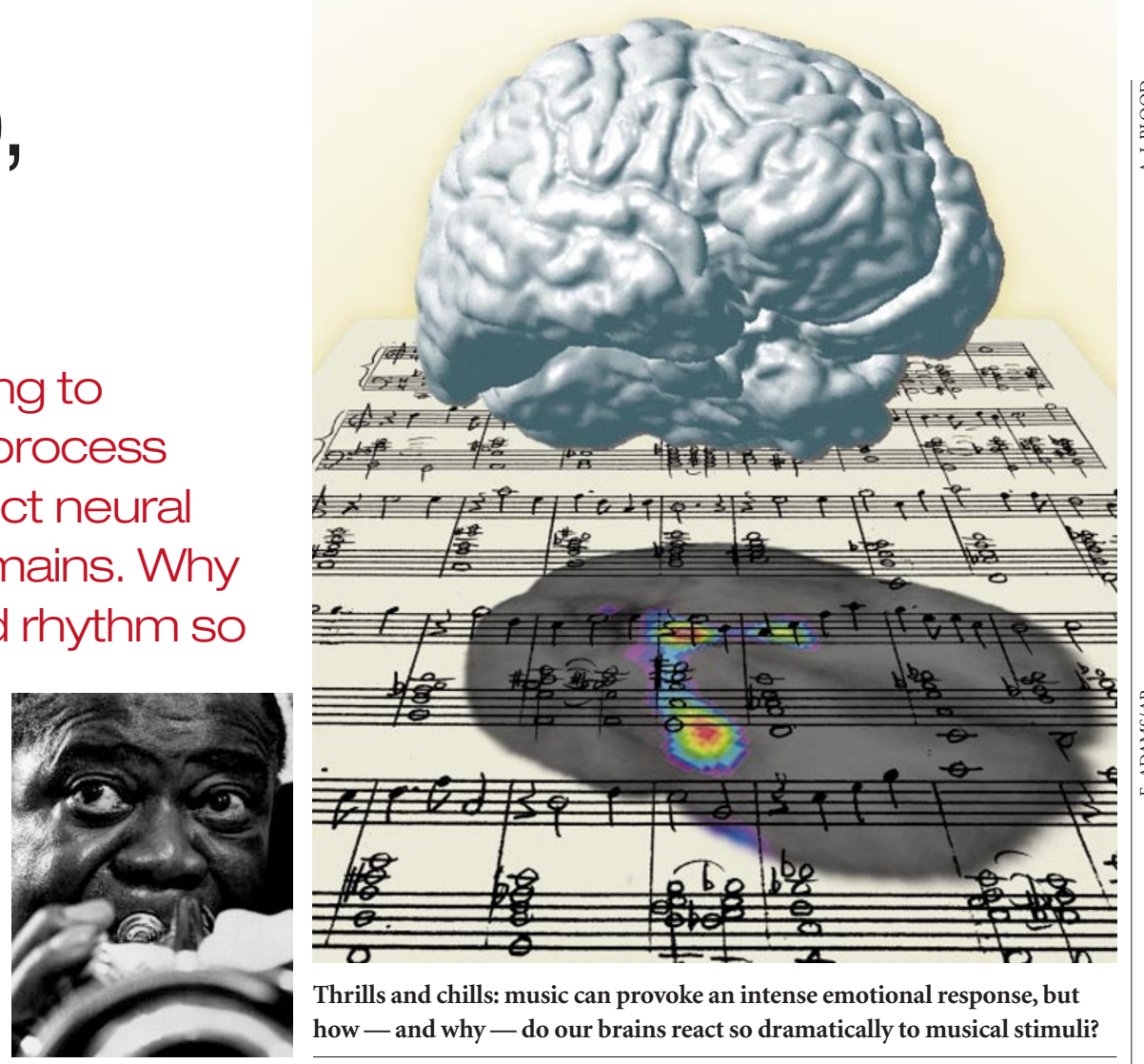

Thrills and chills: music can provoke an intense emotional response, but how — and why — do our brains react so dramatically to musical stimuli?
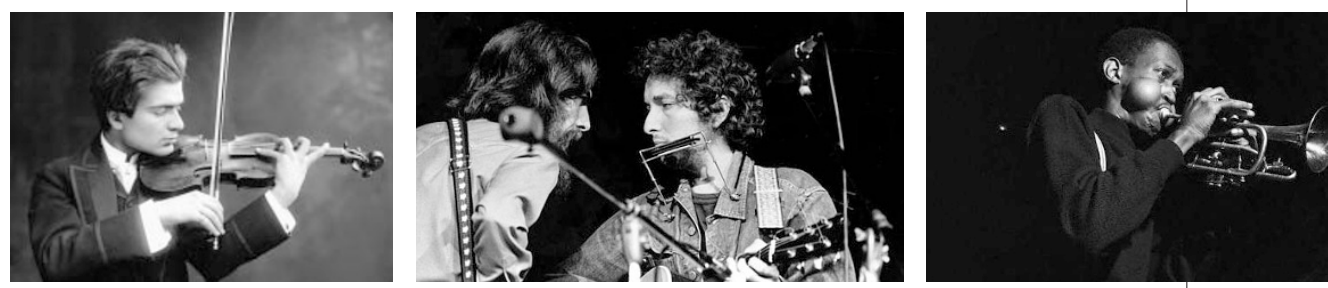

fold of tissue known as the lateral sulcus (see figure, opposite). For one thing, it requires a working memory, where snatches of music can be stored while the brain makes sense of the whole tune. This memory is likely to be located elsewhere in the temporal lobes and towards the rear of the frontal lobes ${ }^{2}$, but scientists have not yet pinned this down. Where long-term memories for tunes are stored is even less clear, but they are remarkably resilient: once we have learnt a melody we rarely forget it. And then there is the emotional response to music, which is processed in a set of structures distributed more widely

Making music, as opposed to just listening to it, requires well-honed motor skills, and relies on a high level of integration between auditory inputs and motor control. The fine hand, finger or lip control required to play an instrument are, like all movements, directed by specialized motor areas of the cerebral cortex. Although detailed studies of the brain areas involved in musical dexterity have yet to be conducted, the secondary motor cortex directs more complex motor patterns, such as coordinated finger move- ments, whereas the primary motor complex

Playing an instrument also depends on the brain interpreting somatosensory touch - information from the fingers and lips in contact with the instrument. "The level of motor and sensory processing that goes on in playing and responding to music, in addition to auditory processing, is extraordinary," says Eckart Altenmüller, director of the Institute of Music Physiology and Musician's Medicine in Hanover, Germany. "It is the perfect paradigm of complex human behaviour." In other words, neurological studies of music processing can serve as a model for studying how the brain works more generally.

But such studies have lagged behind those of visual perception. In the 1960s, neuroscientists began to expose animals to features such as patterns of lines, colours and edges, and recorded the subsequent electrical activity in the subjects' brains. From this they could map the precise areas within the visual cortex in which such features are perceived. But these studies are difficult for music, which can only be examined in human volunteers, where it is not possible to place electrodes deep in the brain. What is more, generally handles simpler tasks. 
notes played disappear the moment they are perceived.

"This is why it has been hard to get a handle on music," says Robert Zatorre, director of the Montreal Neurological Institute and Hospital at McGill University in Canada, who began investigating the neurobiology of music two decades ago. He found himself more or less alone in the field until the mid1990s, when others entered the fray. Like Zatorre, who is an organist, most of these researchers are themselves musicians.

What we now know about the neural circuits that process music has mostly been determined by using the brain imaging techniques of positron emission tomography (PET) and functional magnetic resonance imaging, which can determine the anatomical location of activity within the brain. Other methods include electroencephalography and magnetoencephalography (MEG), which respectively measure electrical or electromagnetic activity of neurons within the cerebral cortex that lie close to the skull. Musical deficits in braindamaged patients - those who have suffered a stroke or have had all or part of their temporal lobes removed to treat epilepsy - have also yielded insights.

\section{Three-part harmony}

Using these techniques, neuroscientists have studied activity in the auditory cortex in response to music ${ }^{3}$. Although the distinctions between the anatomical location of different levels of processing have not been as well defined as for vision, the primary cortex, which receives input from the ear from a structure called the thalamus, is mainly thought to identify the fundamental elements of music, such as pitch and loudness. The secondary cortex is believed mainly to focus on harmonic, melodic and rhythmic patterns, and the tertiary auditory cortex is thought to integrate these patterns into an overall perception of the music.

Studies have also revealed that music is processed by specific neural circuits that might overlap with language and other higher functions, but are certainly not subservient to them. For example, the higher levels of music perception are, like many

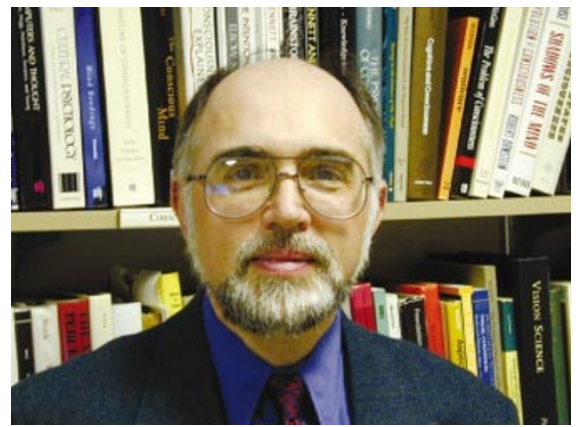

All in the mind: Robert Zatorre has pioneered research into the neurobiology of music.

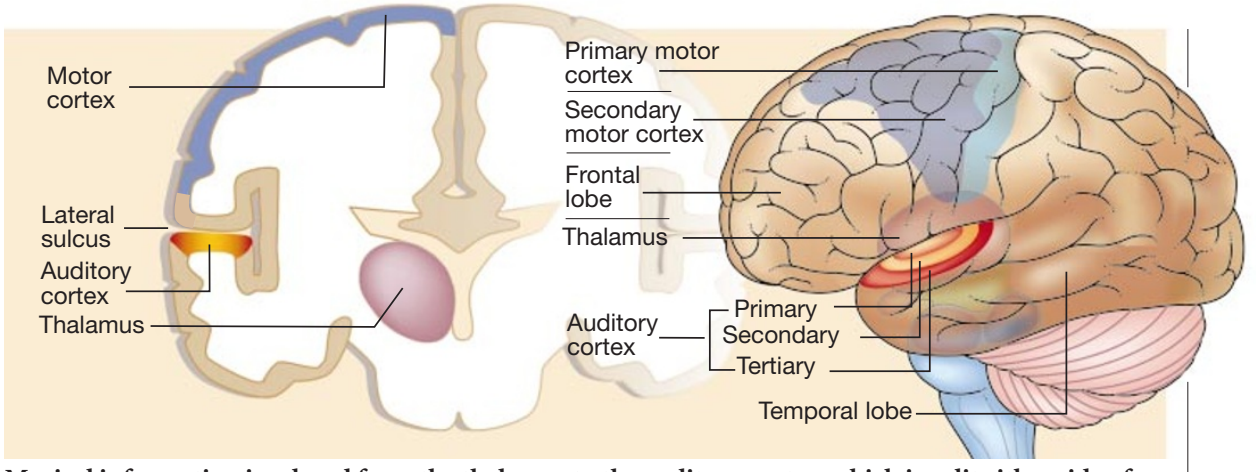

Musical information is relayed from the thalamus to the auditory cortex, which is split either side of the brain. To play, musicians must integrate this information with signals from the motor cortex.

sophisticated cognitive tasks, to some extent 'lateralized' - that is, they take place predominantly in one side of the brain. Language is predominantly processed in the left hemisphere, along with a variety of reasoning tasks, but in most people the higher levels of musical perception take place predominantly in the right hemisphere ${ }^{4}$, where the processing of emotional and spatial information takes place. There is also evi-

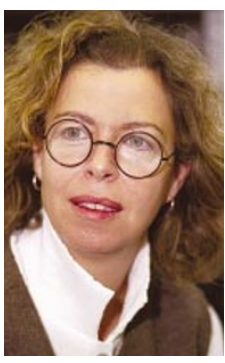

Isabelle Peretz sees tone deafness as a highly specific neural disorder. dence of some lateralization at the level of the auditory cortex ${ }^{3}$.

Last month, a team led by Isabelle Peretz of the University of Montreal provided further evidence of the distinctive nature of the pathways involved in perceiving music ${ }^{5,6}$. Peretz, herself a classical guitarist, studied intelligent and articulate subjects with congenital amusia - commonly known as 'tone deafness', whose sufferers have reportedly included Theodore Roosevelt and Che Guevara.

None of Peretz's subjects noticed when a note in a tune was changed by a semitone. And they were unmoved by dissonance, combinations of notes that sound unpleasant to most people. But the volunteers could all recognize the pitch changes that convert a statement, such as 'He speaks French', into a question: 'He speaks French?'

In addition, most of Peretz's amusical subjects could neither be taught nor remember a melody, and most could not tap in time to a tune. "It is an extraordinarily specific disorder, confined to the musical domain," says Peretz. "We think that congenital amusia results from some disruption of the wiring in the auditory cortex, but we'll have to do more detailed functional neuroimaging studies to understand exactly what has gone wrong."

The neural circuits associated with music can run independently of input. Everyone sings to themselves - and who hasn't experienced the irritating phenomenon of being unable to get a tune out of their head? Andrea Halpern, an experienced singer and a cognitive psychologist at Bucknell University in Lewisburg, Pennsylvania, has used PET to observe the brains of subjects as they imagined a specified melody. She found that the areas activated were similar to those that responded when music was played - except for the primary auditory cortex, which remained quiet". "The signals are weaker, but the music is played in real time, and subjects react in much the same way as they do when listening to music," says Halpern.

With this basic knowledge to hand, neuroscientists are starting to use studies of music processing to address some of the big questions in brain research. One is the extraordinary plasticity of the cerebral cortex, which allows us to learn new skills. Using MEG, for instance, Christo Pantev of the University of Münster in Germany and his colleagues showed in 1998 that a much larger area of the auditory cortex was activated in musicians on hearing a piano tone compared with non-musicians. The earlier the age at which the musicians had begun to practise, the greater the enlargement ${ }^{8}$.

Now at the Rotman Research Institute in Toronto, Canada, Pantev has shown that the training effect depends on the instrument involved. Last year, in a study of trained violinists and trumpeters, he saw that the enlarged area of activity in the auditory cortex was smaller when the violinists listened to trumpet tones, and vice versa, than when each listened to the sound of their own instrument ${ }^{9}$.

\section{Senses working overtime}

In other experiments, conducted with Thomas Elbert of the University of Constance in Germany, Pantev has shown that skilled violinists give over a larger area of their somatosensory cortex to represent each of the four fingers used to hold down their instruments' strings than do nonmusicians. The precise location of this region was also shifted compared with nonmusicians, and again, the magnitude of these changes correlated with the age at which the violinists had started playing ${ }^{10}$. In trained musicians, the area of the motor 


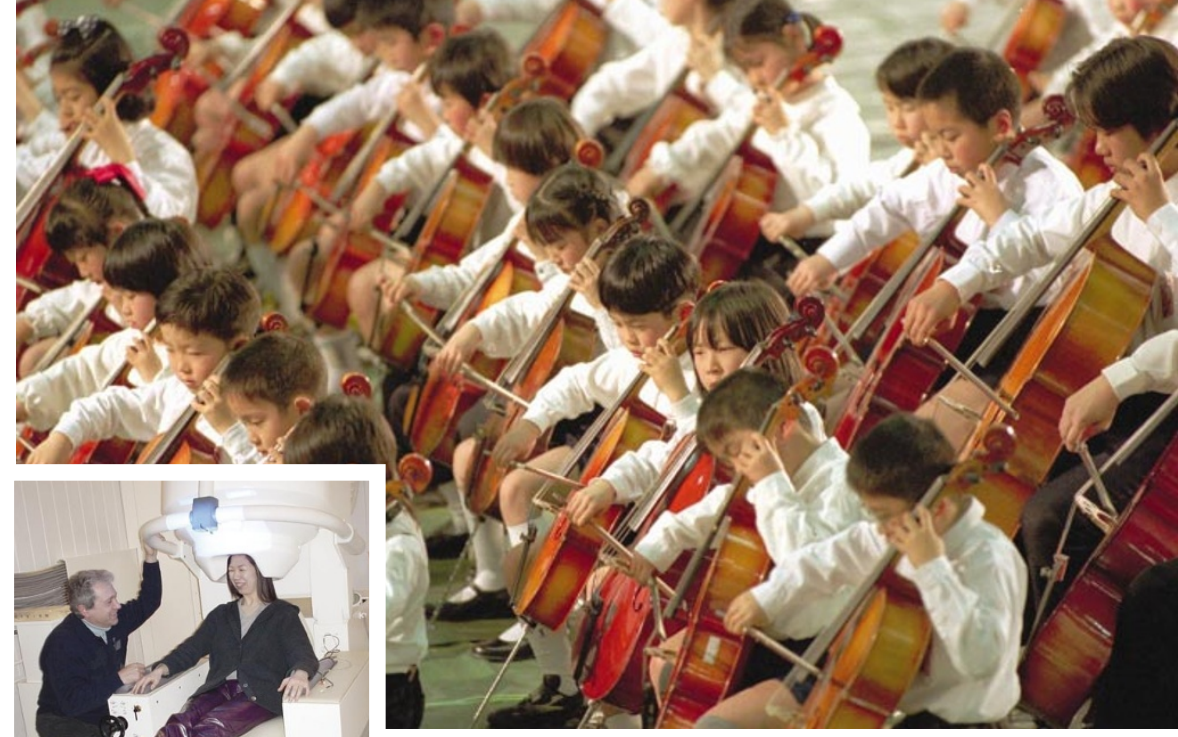
merged" "This mo much movement, and may indicate a biological limit to how far we can develop our musical skills," says Altenmüller.

Although training undoubtedly rewires the cerebral cortex, it is still unclear whether training alone can create talented musicians, or whether it just makes inherently talented people better.

\section{Hothouse flowers}

To investigate this further, Pantev is now embarking on a study of children at the Suzuki School of Music in Toronto and Hamilton. This is a hothouse conservatory, which takes children from the age of four. Pantev's team will study the anatomical location of the children's brain activity in response to music, as well as their perceptual and cognitive skills, before they start training, and follow their development over the years. This will be a decisive study, says Zatorre, who suspects that it will reveal musical ability to be a "bit of nature, a bit of nurture, like everything else".

Evidence that musical ability has some heritable component came last year, from a study of 136 pairs of identical twins and 148 pairs of non-identical twins. Within pairs, the performance of the identical twins in a task of identifying melodies with an incorrect note was more closely matched than for the non-identical twins ${ }^{13}$.

But the deepest mystery is why music is so emotive. Most of us have experienced the

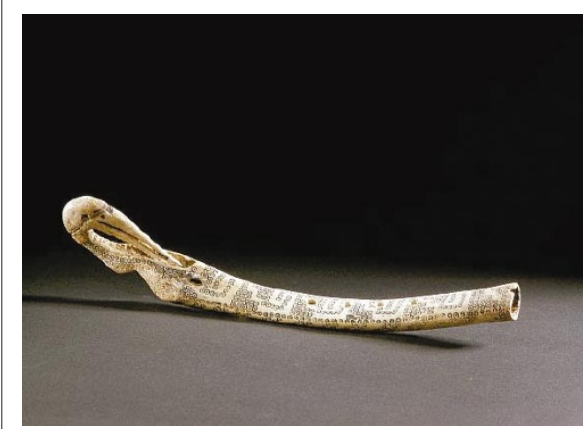

Same old song: music has played an important role for millennia. Instruments similar to this bone flute have been found at Neanderthal sites. 'chills', when a piece of music sends shivers down your spine and raises the hair on your skin. "When you ask people why they listen to music, they invariably refer to some emotion," says Zatorre. "But emotion has been ignored in music research until recently, because it is so very hard to study."

Zatorre has led the way. Initially, he focused on negative emotion, working with Anne Blood, then also at the Montreal Neurological Institute and Hospital. "Musical tastes are so personal that it was easier to design an experiment involving the sort of musical feature everyone dislikes - dissonance - rather than finding what everyone will respond to positively," says Zatorre. His and Blood's PET study on 10 volunteers showed different patterns of activation in specific brain areas known to be involved in emotional processing, in response to consonant and dissonant melodies ${ }^{14}$. These areas are separate from the auditory cortex, indicating that the recognition of music and its emotional appreciation use different neural pathways.

\section{Hit parade}

But Zatorre and Blood, who is now at the Massachusetts General Hospital in Charlestown, are most interested in understanding the positive side of musical emotion. In a more recent PET study, 10 music students listened to pieces of music they had individually chosen for their powerful, but very personal, emotional impact. The pieces activated neural pathways similar to those associated with euphoria and reward, which are also activated in response to other pleasurable activities - eating and sex, for example ${ }^{15}$.

Although eating and sex are directly related to survival and reproduction, it remains unclear why evolution should have shaped our brains to derive pleasure from music. Most explanations argue that music plays a key role in social cohesion, or that it promotes the development of motor and perceptual skills that are crucial to survival. More fancifully, some scientists have even suggested that a mother's singing can cause her baby's hair to stand on end and so keep it warm.

Whatever the function, many of the neuroscientists studying music are convinced that it is the product of evolutionary design. "The emotional processing of music probably does have an evolutionary basis," says Altenmüller. "The chills can be so profound, so biological, it seems very likely that the evolutionary point is about social cohesion."

Pinker remains unconvinced, arguing that our appreciation of music and our musicianship are by-products of the way our auditory system analyses sounds, combined with our tool-making skills. "The problem with most of the theories put forward is that they are circular," he says.

The true answer may never be known. "We can't do the experiment to re-evolve ourselves," observes Halpern. Thankfully, we don't need to understand the evolutionary significance of music, nor the details of how it is processed in the brain, for it to continue to work its magic. As Elvis Presley once said: "I don't know anything about music. In my line you don't have to."

Alison Abbott is Nature's senior European correspondent.

1. Pinker, S. How the Mind Works (Norton, New York, 1997).

2. Zatorre, R. J., Evans, A. C. \& Meyer, E. J. Neurosci. 14, 1908-1919 (1994).

3. Zatorre, R. J., Belin, P. \& Penhune, V. B. Trends Cogn. Sci. 6,

4. Peretz, I. in Music and Emotion: Theory and Research (eds Juslin, P. \& Sloboda, J.) 105-134 (Oxford Univ. Press, 2001).

5. Ayotte, J., Peretz, I. \& Hyde, K. Brain 125, 238-251 (2002).

6. Peretz, I. et al. Neuron 33, 185-191 (2002).

Zatorre, R. J., Halpern, A. R., Perry, D. W., Meyer, E. \&

Evans, A. C. J. Cogn. Neurosci. 8, 29-46 (1996).

8. Pantev, C. et al. Nature 392, 811-814 (1998).

9. Pantev, C., Roberts, L. E., Schulz, M., Engelien, A. \& Ross, B. NeuroReport 12, 169-174 (2001).

10. Elbert, T., Pantev, C., Wienbruch, C., Rockstroh, B. \& Taub, E. Science 270, 305-307 (1995) 12. Elbert, T. et al. NeuroReport 16, 3571-3575 (1998).

13. Drayna, D., Manichaikul, A., de Lange, M., Snieder, H. \& Spector, T. Science 291, 1969-1972 (2001).

14. Blood, A. J., Zatorre, R. J., Bermudez, P. \& Evans, A. C. Nature Neurosci. 2, 382-387 (1999).

15. Blood, A. J. \& Zatorre, R. J. Proc. Natl Acad. Sci. USA 98, 11818-11823 (2001) 37-46 (2002).

11. Amunts, K. et al. Hum. Brain Mapping 5, 206-215 (1997) 